\title{
Barriers towards reducing domestic energy consumption - findings of a study among social housing tenants
}

\author{
Gesche M. Huebner* \\ University College London, Energy Institute, \\ 14 Upper Woburn Place, London, WC1H 0NN, UK \\ E-mail: g.huebner@ucl.ac.uk \\ *Corresponding author

\section{Justine Cooper}

School of Architecture, Design \& Construction, University of Greenwich,

Avery Hill Campus, Mansion Site,

Bexley Road, Eltham, London, SE9 2PQ, UK

E-mail: Justine.Cooper@gre.ac.uk

\author{
Amy Moon and Pamela Maras \\ School of Health and Social Care, \\ University of Greenwich, \\ Avery Hill Campus, Mansion Site, \\ Bexley Road, Eltham, London, SE9 2PQ, UK \\ E-mail: A.Moon@gre.ac.uk \\ E-mail: P.F.Maras@gre.ac.uk
}

\author{
Keith Jones \\ School of Architecture, Design \& Construction, \\ University of Greenwich, \\ Avery Hill Campus, Mansion Site, \\ Bexley Road, Eltham, London, SE9 2PQ, UK \\ E-mail: k.g.jones@gre.ac.uk
}

\begin{abstract}
The aim of this study was to take a broad approach to understanding domestic energy consumption and identify difficulties in energy reduction. The study focused on a variety of factors, including barriers and motivators for behaviour change, comfort and comfort actions and knowledge about the heating system. Data collection was carried out with 55 social housing tenants in England using interviews and questionnaires. Data showed that tenants were to a large degree already engaged in energy-saving actions. 'Warmth' was the most important aspect of comfort for the majority of tenants but about half of both comfort actions and actions against cold were not energy-intensive. 'Habit' was identified as the most important barrier to behaviour change whilst 'money' was seen as the greatest motivator. A deficit regarding quality and
\end{abstract}


quantity of instructions on the usage of the heating system emerged. The results imply that social housing landlords have the responsibility to provide better instructions on the most efficient home operation. They could play a large role in changing tenants' habits, for example when implementing physical changes to the dwelling.

Keywords: energy consumption; behaviour change; social housing; comfort; habit; heating system; social housing tenants.

Reference to this paper should be made as follows: Huebner, G.M., Cooper, J., Moon, A., Maras, P. and Jones, K. (2014) 'Barriers towards reducing domestic energy consumption - findings of a study among social housing tenants', Int. J. Environment and Sustainable Development, Vol. 13, No. 4, pp.425-448.

Biographical notes: Gesche M. Huebner was a Research Fellow in the Sustainable Built Environment Research Group (SBERG) at the University of Greenwich at the time of writing this paper. She holds a PhD in Psychology. She is now working as a Research Associate at the University College London, Energy Institute.

Justine Cooper is a Research Fellow in the SBERG at the UoG. Justine's background is BEng in Civil Engineering (Hons) and MSc in Building Rehabilitation and she worked as a Private Sector Contract and Consultant Engineer before joining the university in 2006.

Amy Moon is the Lead Research Fellow within the Research Centre for Children, Schools and Families. She is a member of the British Psychological Society and she is completing a $\mathrm{PhD}$ investigating student wellbeing at university.

Pamela Maras is a Professor in Social and Educational Psychology at the University of Greenwich where she is the Head of the Department of Psychology and Counselling and Director of the Research Centre for Children Schools and Families. She is a Chartered Psychologist and Fellow of the British Psychological Society.

Keith Jones is Professor of Facilities Management and leader of SBERG. His expertise covers a range built environment and management issues with a focus on sustainability. He was the principal investigator on this project.

\section{Introduction}

To achieve the UK's commitment to reduce its greenhouse gas emissions by $80 \%$ in 2050, it is of prime importance to understand how people use energy in their homes: in the UK, $27 \%$ of all carbon emissions stem from domestic households. Space heating (53\%), appliances and lighting (22\%) and water heating (20\%) make up the largest share of the energy consumption in private homes (HM Government, 2006). Household energy consumption depends on many factors including building design and condition, preferred internal temperature, actions to keep warm and cool, the importance given to energy conservation, knowledge about the consequences of increased energy consumption, to name a few. While a large number of studies have investigated factors related to energy consumption and energy savings, they have often limited their approach to certain types 
of variables such as those associated with socio-demographic, building or psychological factors. The aim of this paper is to review those variables which have been identified as impact factors on domestic energy consumption; to discuss potential new factors; and to present a study that started to assess the impact of these factors. The target group for the study consisted of social housing tenants who are generally financially less well-off and who will hence potentially suffer more from increasing energy prices. Whilst the UK Government has made combating fuel poverty a priority and has established a number of measures to meet this aim (Department of Energy and Climate Change, 2009), little research has been carried out on how social housing tenants use energy and perceive energy consumption. This study addresses this gap in knowledge.

\subsection{Socio-demographic variables}

A number of studies reported that higher income was related to higher energy consumption (Druckman and Jackson, 2008; Gatersleben et al., 2002; Abrahamse and Steg, 2009; Poortinga et al., 2004). Household composition was another significant factor with the more people in the household, the greater the energy use (Gatersleben et al., 2002; Druckman and Jackson, 2008). Thus a larger household uses more energy but is also more energy-efficient: the per capita use is lower in a larger household (Druckman and Jackson, 2008; Yohanis et al., 2008). Gatersleben et al. (2002) found that age was negatively related to energy consumption whereas Abrahamse and Steg (2009) did not find a significant relationship between age or gender and energy consumption. While the demographic variables of income and household size were related to energy consumption, they showed no relationship to energy savings (Abrahamse and Steg, 2009).

Taken together, higher income and a larger household are unequivocally associated with greater energy consumption, even though the latter also means greater energy efficiency. However, they are not related to energy savings, meaning that whilst they can contribute to explaining energy consumption, they cannot predict energy savings where psychological variables are assumed to be of greater importance.

\subsection{Psychological variables}

Several social-psychological theories have been put forward to explain pro-environmental behaviour such as the theory of planned behaviour (TPB) (Ajzen, 1991), the norm-activation-model (NAM) (Schwartz, 1977) and the value-belief-normtheory (VBNT) (Stern, 2000). In the TPB, behaviour is ultimately the consequence of the intention that is the motivation to perform the behaviour in question. The behavioural intention in turn is determined by the attitude towards the behaviour - i.e., its valuation the perceived behavioural control, i.e., the perceived ability of performing the behaviour in question and the subjective norm, i.e., the perception of how favourable or unfavourable others would judge engaging in the behaviour at question. The TPB has been successful at explaining a wide range of behaviours, with perceived behavioural control the strongest predictor [for a review, see Armitage and Conner (2001)]. For examples, variables of the TPB successfully explained car use (Bamberg and Schmidt, 2003), conservation behaviour (Kaiser et al., 2005), using energy-saving light bulbs (Harland et al., 1999) and household recycling (Kaiser and Gutscher, 2003) even though the amount of variance in the behaviour in question was increased upon inclusion of other 
variables (Harland et al., 1999). Abrahamse and Steg (2009) showed that while variables of the TBP hardly contributed to explaining variation in energy usage, they contributed significantly to explaining total energy saving, with perceived behavioural control as the most important factor.

The NAM was originally used to explain helping or altruistic behaviour (Schwartz, 1977). In this model, behaviour arises when personal norms are activated which reflect an individual's conviction that acting in a certain way is right or wrong (Bamberg et al., 2007). The activation of personal norms occurs when a person becomes aware of negative consequences to other people or entities such as the environment and the person ascribes the responsibility to himself to alleviate those consequences. The NAM has been successfully applied in the explanation of different pro-environmental behaviours (Guagnano and Stern, 1995; Hopper and Nielsen, 1991; Vining and Ebreo, 1992). Regarding energy conservation, Abrahamse and Steg (2009) reported that only the component ascription of responsibility explained additional variance in energy savings after variables of the TBP had been considered.

In the VBNT (Stern, 2000) personal norm, i.e., feeling morally obliged to do something, immediately precedes behaviour. This personal norm is activated by specific beliefs about the consequences of an event and the ascription of responsibility, i.e., the belief that the individual can have some impact with his behaviour. These two specific beliefs in turn depend on a more general belief on the relationship between humans and nature, often measured with the new environmental paradigm (NEP) (Dunlap et al., 2000; Dunlap and van Liere, 1978). Value orientations - often operationalised as altruistic, egoistic and biospheric (de Groot and Steg, 2008) - are the first element in the hierarchical model of the VBNT, preceding the environmental worldview as measured with the NEP. The value basis of pro-environmental behaviour has been researched extensively (e.g., de Groot and Steg, 2007, 2008; Schultz and Zelezny, 1999; Stern and Dietz, 1994; Stern et al., 1995) and results generally indicate that individuals who give greater importance to pro-social, altruistic or biospheric value orientations over egoistic ones, are more likely to show pro-environmental intentions and actions. Several studies used all (Steg et al., 2005) or some (e.g., Stern et al., 1999; Nordlund and Garvill, 2003; Gärling et al., 2003) of the components of the VBNT successfully to explain different pro-environmental behaviours. However, Kaiser et al. (2005) reported a significantly higher explanation of variance in behaviour using TPB instead of VBNT. The literature review found no study that explicitly tested the VBNT to explain energy consumption or savings.

Many energy consumption behaviours, such as switching off lights can be assumed to be under habitual control (Maréchal, 2010), that is, they occur automatically and sub-consciously making habit a potentially import variable in understanding pro-environmental behaviours such as energy savings. However, none of the models discussed incorporate this concept. One aim of this study was to assess how different barriers including habit are judged in their importance towards a change in behaviour and to see if they can be related to other variables of models of pro-environmental behaviour.

Another aspect that is potentially of great importance in understanding energy usage is the knowledge about the correct usage of energy in the home, such as the most efficient operation of the heating system and its components. Liao et al. (2005) found that most of the interviewed occupants did not know what thermostatic radiator valves (TRVs) were and how they should be operated; a walk-through questionnaire showed that more than $65 \%$ of all TRVs were set on too high a value. This study aimed at finding out if tenants 
had received proper instructions about the usage of their heating system which is a potential prerequisite to using the system adequately.

\subsection{External and stock conditions}

External temperature impacts average energy consumption with higher consumption being associated with lower external temperatures. Consequently, geographical location and a rural vs. urban setting have an impact on energy consumption. In addition to these external variables, housing design also impacts energy consumption. Heat loss is greatest for detached houses, followed by semi-detached and terraced houses and then by bungalows. Flats are most energy-efficient, with a lower heat loss than other types of dwelling (Shorrock and Utley, 2008), as they have less external wall area in relation to floor area. By 2006, 91\% of all UK homes had central heating with $87 \%$ having gas central heating which is generally the most efficient heating system (Shorrock and Utley, 2008).

The standard assessment procedure (SAP) is the UK-wide system used for energy rating of dwellings. The higher the value, the better the energy efficiency of a building and the lower the annual energy costs. Over the last decades the average SAP rating of homes has increased, partly due to the building of new, more energy-efficient stock but mainly due to upgrades of the existing stock, e.g., through better insulation or more efficient heating systems. The current average SAP rating for British homes is 51.6; a value of 100 corresponds to a zero-energy home. Higher values can be achieved when a dwelling is a net exporter of energy (Department of Energy and Climate Change, 2011).

However, whilst the design and condition of a building has to be kept in mind when trying to understand energy consumption, these are far from being the sole determinants of the amount of energy consumed in a dwelling, as even in very similar dwellings, large differences in energy consumption have been observed and attributed to the behaviour of inhabitants (Gill et al., 2010).

\subsection{Comfort}

Comfort is inextricably linked to energy consumption and thus to climate change (Chappells and Shove, 2005); however, hardly any research has looked at what comfort means to home occupants, how they achieve an adequate level of comfort and if and how these practices are linked to energy consumption. In this introductory paragraph, the concept of comfort is described and the potential importance on energy consumption highlighted. Comfort is generally defined as the condition of mind which expresses satisfaction with the environment and encompasses a minimum of six dimensions: thermal; air quality; visual; acoustic; ergonomic; and psychological comfort (ASHRAE, 2010). Regarding domestic energy consumption, thermal comfort is potentially of greatest importance as the largest share of energy in the home is used for heating (and in other parts of the world for cooling). Hence, understanding what aspect of comfort tenants judge as most important and how they create comfortable conditions, should lead to the identification of further variables predicting domestic energy consumption and the design of interventions to reduce energy consumption. Whilst early work on thermal comfort [since Fanger $(1967,1970)$ ] focused on creating a set of standard comfort conditions designed to match physiological needs, resulting in "provision and maintenance of a fixed set of thermal, luminous and acoustic conditions" [Cole et al., 
(2008), p.324], it was soon recognised that building occupants were thermally content with conditions outside the range of 'comfortable temperatures' predicted by laboratory findings (e.g., Busch, 1992; Sharma and Ali, 1986). These findings have promoted the emergence of an 'adaptive comfort theory' to explain the impact that contextual factors and past thermal history have on occupants' thermal preferences (e.g., Brager and de Dear, 1998; de Dear and Brager, 2001; van Hoof et al., 2010). One such factor known to increase satisfaction with thermal comfort is the access to controls (e.g., Brager and de Dear, 1998; van Hoof et al., 2010).

The research on comfort has broadened since its early days, taking variations in individual behaviour and the social and cultural dimensions of comfort practices into account. As Shove et al. (2008, p.307) states, there currently exists "an unusually interdisciplinary attempt to show how technological infrastructures (existing and new); policy assumptions (about the status quo and the future); conventions of body and self; and real-time interaction with 'the weather' and everyday environments intersect in the production of comfort".

Only a few studies have explicitly examined the relationship between comfort and energy consumption on an individual level, e.g., Seligman (1978) reported that personal comfort and health concerns were the best predictors of energy consumption for air-conditioner use. A general finding is increasing indoor temperatures from an average winter internal temperature of $13^{\circ} \mathrm{C}$ in the early 1970 s to about $17.5^{\circ} \mathrm{C}$ in 2006 (Shorrock and Utley, 2008), indicating that much warmer temperatures are now preferred and have become the norm.

Taken together, whilst comfort definitions and actions can be expected to play a role in explaining domestic energy consumption; the current level of knowledge on the specific meaning of comfort in the home and its linkage to energy consumption is low. The final aim of this study was to understanding what comfort means to tenants and how they achieve a desirable level of comfort in their home.

\subsection{Social housing tenants}

The participants of this study were all living in social housing accommodation. Social housing tenants make up about $18 \%$ of the UK's population and are characterised by a lower-than-average-income and economic inactivity; with a large proportion of elderly tenants, members of ethnic minorities and single parents (Department for Communities and Local Government, 2008, 2009). Local Authorities may also add groups to the housing act list at their discretion (Rutter and Latorre, 2009). The Decent Homes Standard (DHS) required all social homes to be 'decent' by the end of 2010. For a home to be decent it must meet all current statutory minimum standards for housing, be in a reasonable state of repair have reasonably modern facilities and services and provide a reasonable degree of thermal comfort (Department for Communities and Local Government, 2006). Socially rented homes are generally in better condition than privately rented homes. Energy consumption is generally lower in registered social landlords (RSL) rented dwellings and comparable for privately rented and local authority rented accommodation; with owner-occupied dwellings having by far the highest average energy consumption. Energy consumption in general (and in social housing) has remained stable over the last few years indicating that energy-saving improvements such as insulation have been negated by a higher demand for energy, e.g., for higher internal temperatures and more appliances (Utley and Shorrock, 2006). However, a literature 
search found no studies that focussed on social housing tenants' attitudes towards energy reduction despite the fact that they are generally on low incomes and are vulnerable to fuel poverty, (i.e., they have to spend more than $10 \%$ of their income on energy). Thus, understanding how these tenants use energy in their home and exploring the scope for reductions in energy consumption through behavioural change could increase their disposable income and improve their quality of life.

\subsection{Interim summary and aims of the study}

Research in the last 40 years has identified a number of factors related to pro-environmental behaviour and in particular energy consumption, which can be broadly clustered in the areas of socio-demographic variables, psychological variables and building characteristics. However, even in combination, the identified variables only partially explain the variance observed in energy consumption, indicating that other factors presumably play a role. The current study does not aim at replicating previous results but focuses on exploring other factors that potentially play a role. One of these factors is comfort which has a potentially large impact on energy consumption but has been little researched. Also, knowledge about the heating system was investigated. Ratings of the importance of different barriers and motivators for reducing energy consumption were measured as they are potentially of great importance in changing behaviour but rarely considered in current models of pro-environmental behaviour. Self-reported behaviours and behavioural intentions regarding sustainability in the home were also assessed to gain an understanding of the potential room for energy-savings through behaviour change in this little researched sample of social housing tenants. This project was funded by the UK Engineering and Physical Sciences Research Council.

\section{Methods}

$N=55$ social housing tenants of one local authority and three different RSL took part in a project aimed at understanding and reducing energy consumption in the domestic sphere. Tenants were recruited through notifications in their landlords' newsletters $(0.05 \%$ response rate), resident association meetings (20.00\% response-rate), letters to tenants $(0.50 \%$ response-rate) and a letter-drop in a specific neighbourhood $(1.00 \%$-response rate). Tenants were offered the opportunity to be involved in a six-month study which aimed to understand how they used their home, kept comfortable and could potentially reduce their energy consumption through no-cost, non-technological, non-invasive interventions targeting behaviour. Most participants lived in rural areas in Northern England.

The data presented in this paper was collected during an initial home visit to the tenants between March and June 2010 by the first and second author of this paper. Each visit lasted about one and a half to two hours. After an introduction to the project, tenants filled in a questionnaire at their own pace. Then a semi-structured interview was carried out asking questions about energy consumption and comfort practices. It cannot be ruled out that filling in the questionnaire first could have impacted on the answers in the interview. However, only one item was assessed both with the questionnaire and the interview, namely engaging in energy-saving actions. The other variables hardly overlapped and had different foci; hence, no problematic impact was expected. A tour of 
the home rounded up the visit and gas and electricity meter readings were taken. Information about the stock condition was provided by the landlords. Details about the questionnaire and the interview are given below. In cases in which not all the $N=55$ participants answered a question, the valid $N$ is stated.

\subsection{Background information}

Background information reflects the data provided by the head of the household $(\mathrm{HoH})$, who was defined as the person who initiated and led the involvement in the research project. Of the $\mathrm{HoH}, 54.50 \%$ were female and $45.50 \%$ male. The mean age was $M=64.26(S D=11.02)$. This above-average mean age is reflected in the finding that $50.00 \%$ were retired. $24.10 \%$ were in fulltime-employment, $14.80 \%$ in part-time employment, $7.40 \%$ were disabled and $3.70 \%$ were a carer for a relative $(N=54) .58 .00 \%$ of all households were single-person households, $31.00 \%$ two-person-households, $9.00 \%$ three-person-households and the remaining $2.00 \%$ four or more-person-households. $50 \%$ of all dwellings were flats, $24.00 \%$ houses, $20.00 \%$ bungalows and the remaining $6.00 \%$ were classified as other. The average SAP-rating was $M=67(S D=12.50)$ with a range from 38 to 82 . All but three participants were of British White origin and only one single-parent household participated. Hence, of the three main groups of social housing tenants, namely, elderly members of ethnic minorities and single-parents, the segment of elderly participants was strongly overrepresented.

\subsection{Questionnaire}

Participants were handed a printed version of a questionnaire to assess a number of psychological constructs. They completed the questionnaire at their own pace. For all items, the response format was a five-point Likert type scale [strongly agree (1), agree (2), neither agree nor disagree (3), disagree (4), strongly disagree (5)]. For individual items refer to Appendix A. Items with negative phrasing were reversely coded in the analysis. The questionnaire assessed behavioural intentions and behavioural practices relating to energy consumption in the household. It also asked explicitly about perceived barriers to changing behaviour, such as being used to behaving in a certain way, the opinion that saving energy was not useful, that the monetary savings were too little etc. Three statements assessed the motivation to reduce energy consumption for different reasons, e.g., to protect the environment, to keep the planet liveable for future generations and to save money. The intentions and actual behaviour items were adapted and re-worded from the measurement of ecological attitudes and knowledge - revised questionnaire (MEAK_R) (Maloney et al., 1975) to be suitable for a British sample. The behavioural intentions and actual behaviour items that were investigated in this study were chosen to be low-tech, no-costs behavioural actions that were presumed to be applicable to as many tenants as possible. The different motivations to save energy were phrased in such a way as to be located in one of the three value domains that are of importance in pro-environmental behaviour, that is, egoistic, biospheric and altruistic values. For the barriers, the authors of this study independently listed those concepts that they considered of importance, based on their knowledge of literature and then after discussion agreed on those deemed as most important. 


\subsection{The interview}

The interview (Appendix B) sought to understand what comfort meant to participants and how they used energy in the home. All questions were in an open-ended format except for the rating scales. If participants did not answer a question, it was omitted; hence, the number of answers varies for different questions. The first question asked about the meaning of the comfort to the individual and then asked for the most important aspect of comfort. This was followed by a question about what the individual did to keep comfortable (comfort practices). Participants were then asked about their actions when feeling cold (actions cold). A further question assessed whether participants already engaged in energy-saving actions in the home. The type of heating system and the quality of the instructions about its usage were assessed. A final question asked about tenants' general home satisfaction and the satisfaction with the heating system which they rated on a scale from 1 (very dissatisfied) to 10 (entirely satisfied).

\section{Results}

Whilst responses to the questionnaire only needed to be entered into a data file, coding of the answers to the open-ended interview questions was necessary before analysis. All answers were clustered independently by two project members into answer categories that had been created upon initial inspection of the data. If the two researchers disagreed on the classification of a reply, a third project member was consulted. If no agreement was reached, the answer was classified as 'other'.

\subsection{Engagement in energy-saving actions}

Engagement in energy-saving actions was assessed in two ways. The questionnaire contained a scale of eight items describing behaviours on energy usage. The scale reliability expressed as Cronbach's alpha was $\alpha=.65$. The general agreement was high with $M=2.11(S D=0.65 ; N=54)$. Figure 1 shows the mean responses to the individual items assessing self-reported behaviour

The interview contained the open-ended question asking if a participant engaged in energy-saving actions and if so in which ones. $69.40 \%$ of all participants affirmed engagement in energy-saving actions; $58.30 \%$ reported performing at least two energy saving actions. Amongst those stating that they engaged in energy-saving actions using energy efficient light bulbs was mentioned by $73.00 \%$ of participants and switching off lights and appliances by $48.00 \%$. It is noteworthy that most actions were centred on using less electricity and that only one person mentioned using less heating which is generally considered the most efficient way of reducing energy consumption (excluding purchase behaviour). Thus, the general impression gained from this data is that the majority of people were already engaged in energy-saving actions which could potentially limit the success of behavioural interventions. However, it is possible that energy-saving behaviour in the whole social housing sector is less common as participants volunteered to participate in the study and they might represent that segment of people with greater interest and involvement in energy-saving. In any case, the scope for changing behaviour in terms of changing the usage of the heating system is large. 
Figure 1 Mean agreement and SE are depicted on the y-axis. The eight items assessing self-reported behaviour, in abbreviated form and in order of decreasing agreement are shown on the $\mathrm{x}$-axis (see online version for colours)

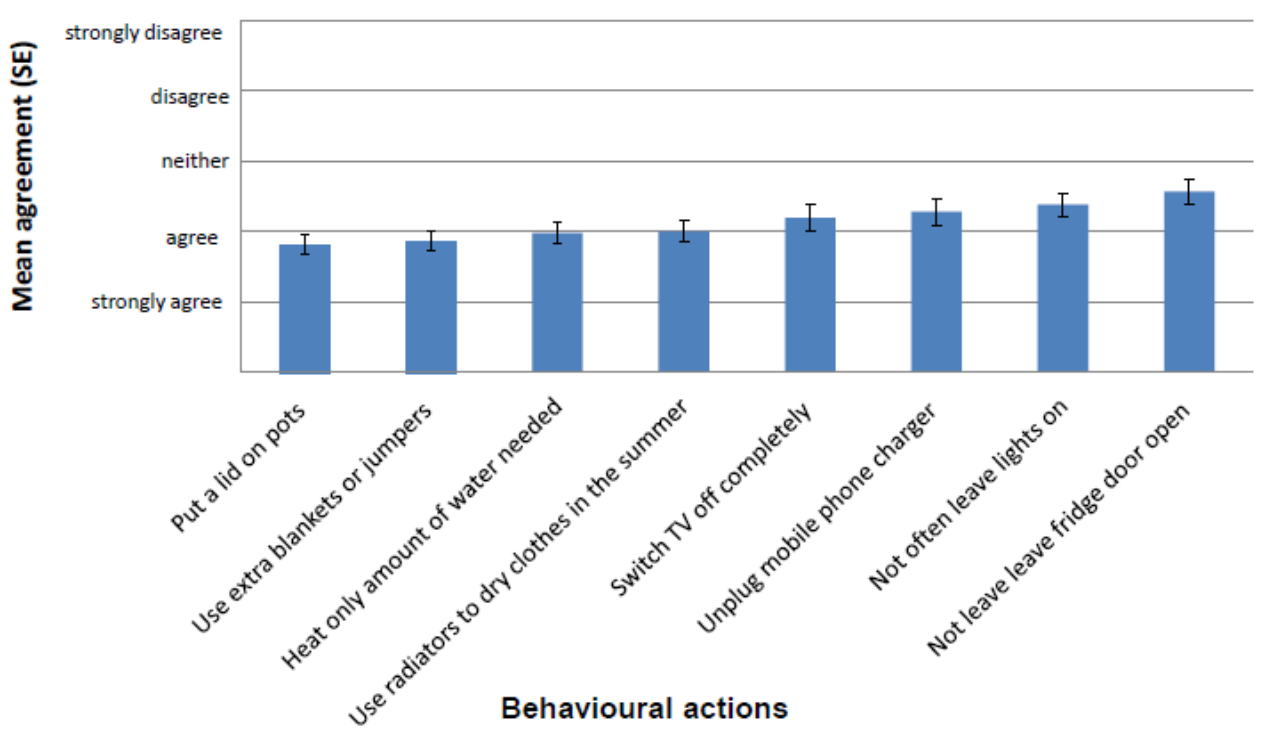

Behavioural intentions, i.e., the willingness to engage in energy-saving actions (for individual items, see Appendix A) was assessed with nine items in the questionnaire and the mean score $M=1.83(S D=0.55)$. Thus, on average, the willingness to engage in energy-saving actions was high.

\subsection{Barriers towards a reduction of energy consumption}

One question in the questionnaire specifically addressed what participants perceived as barriers towards a reduction in energy consumption $(N=50)$. Figure 2 shows the mean agreement with the different barriers, in descending order. While generally participants disagreed with all statements, e.g., judged the proposed barriers as unproblematic, one item stood out: I am used to behaving in a certain way (habit called hereafter). Mean agreement was $M=2.58(S D=0.99)$ as opposed to a mean of $M=3.77(S D=0.54)$ averaged across the other seven items.

A repeated measures ANOVA (with Greenhouse-Geisser adjustment) showed a highly significant main effect of type of barrier, $F(7,343)=15.58, p<.001$. Posthoc pairwise comparisons with Bonferroni adjustment showed that the mean agreement with the habit item was significantly lower than with all other items (all $p<.001$, except for comparison with 'don't know how': $p=.042$ ). Mean agreement with the item 'don't know how' (lack of knowledge hereafter) also differed significantly from 'friends don't do it' $(p=.001)$, 'it takes too much time' $(p=.001)$, 'there is no point' $(p=.005)$. The last remaining difference existed between 'it takes too much time' and 'the money saved is very little' $(p=.001)$.Hence, only one or perhaps two of the proposed barriers were actually perceived as barriers by the participants, namely habit and lack of knowledge. 
Figure 2 The different barriers towards using less energy are shown on the $\mathrm{x}$-axis, in order of decreasing agreement. Mean agreement and se are depicted on the y-axis (see online version for colours)

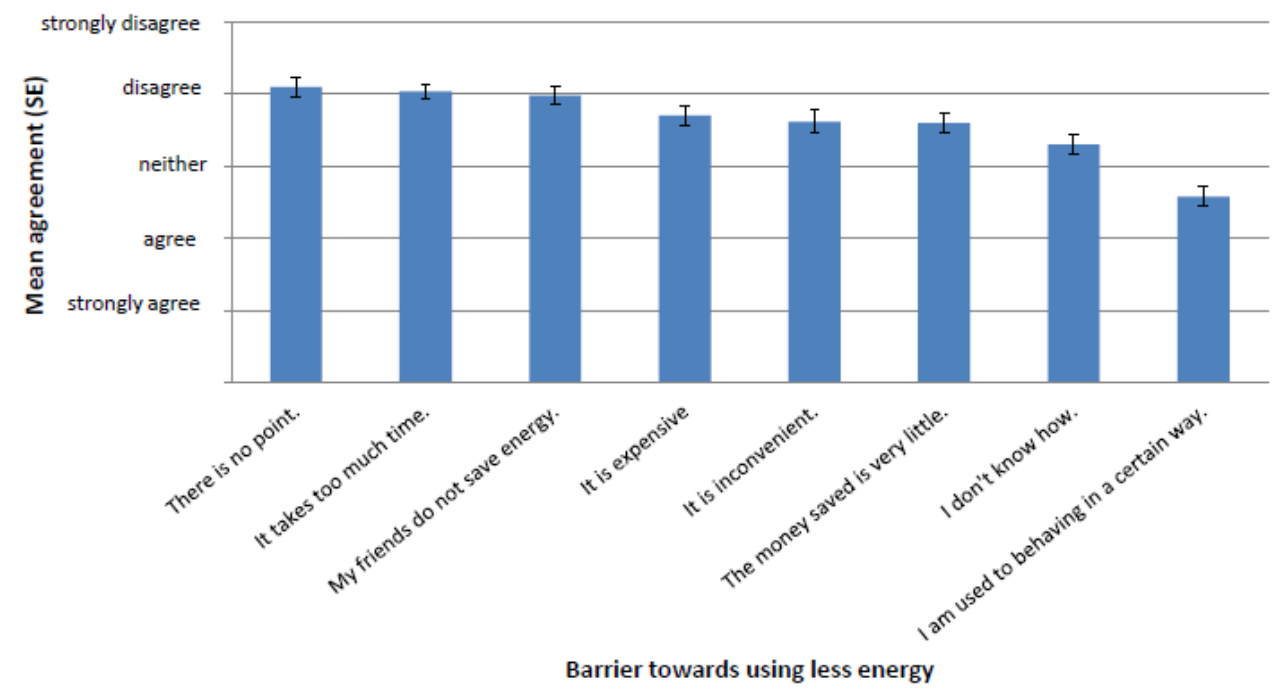

The question then arising was whether this finding was actually meaningful, e.g., related to other variables. A part of the hierarchical model of the VBNT (Stern, 2000) was tested; to explore whether variation in behavioural actions could be explained by behavioural intentions (as in the VBN-model) or by habit or by both behavioural intentions and habit. The results of the hierarchical regression analysis are presented in Table 1.

Table 1 Multiple regression analyses to test which variables explained most variance in self-reported behavioural actions

\begin{tabular}{lccccccc}
\hline & $d f$ & $F$ & $A d j . R^{2}$ & $p$ & $\beta$ & $t$ & $p$ \\
\hline $\begin{array}{l}\text { DV: behaviour } \\
\text { Model 1 }\end{array}$ & 1,52 & 7.58 & .110 & .008 & & & \\
$\begin{array}{l}\text { Behavioural intentions } \\
\text { Model 2 }\end{array}$ & 1,52 & 10.32 & .152 & .002 & & & \\
Habit & & & &. & -.410 & -3.21 & .002 \\
Model 3 & 2,52 & 7.33 & .196 & .002 & & & \\
Behavioural intentions & & & & & .254 & 1.94 & .058 \\
Habit & & & & & -.332 & -2.54 & .014 \\
\hline
\end{tabular}

Habit explained variation in behaviour better than behavioural intentions $\left(\mathrm{R}^{2} .152\right.$ versus .11). Habit and behavioural intentions combined explained the greatest amount of variance $\left(\mathrm{R}^{2}=.196\right)$.

\subsection{Motivation to save energy}

In the questionnaire, three questions asked for different motivations to save energy with different ends; i.e., to save money, to protect the environment, or the keep the planet 
liveable for future generations $(N=54)$. Mean agreement was strongest with save money, $M=1.46(S D=0.54)$ and was virtually the same for protect the environment and keep the planet liveable ( $M=1.80, S D=0.74$, and $M=1.80, S D=0.81$; respectively). A repeated measures ANOVA with Greenhouse-Geisser adjustment showed that the effect of motivation was significant, $F(2,106)=8.60, p=.002 ; \eta_{p}{ }^{2}=.140$. Posthoc comparisons with Bonferroni correction showed significant differences between save money and protect the environment $(p=.004)$ and between money and keep the planet liveable $(p=.013)$. Thus, save money was a stronger motivator than the other two options.

The importance of saving money was also reflected in one question in the interview, namely about the motivation to participate in this study. Of those 44 participants who answered this question, the answer given most often was 'saving money' (18), followed by the wish to be helpful to the research project (16) and curiosity and the desire to learn something (14).

\subsection{Comfort}

In response to the open-ended question about what comfort meant to them, $65.5 \%$ of participants gave 'warmth' as an answer. Figure 3 shows the distribution of answers (multiple answers possible), with the $\mathrm{x}$-axis indicating the percentage of participants who had named the attribute listed on the $\mathrm{x}$-axis.

Figure 3 The y-axis shows the percentage of tenants who had chosen the attribute of comfort as given by the $y$-axis

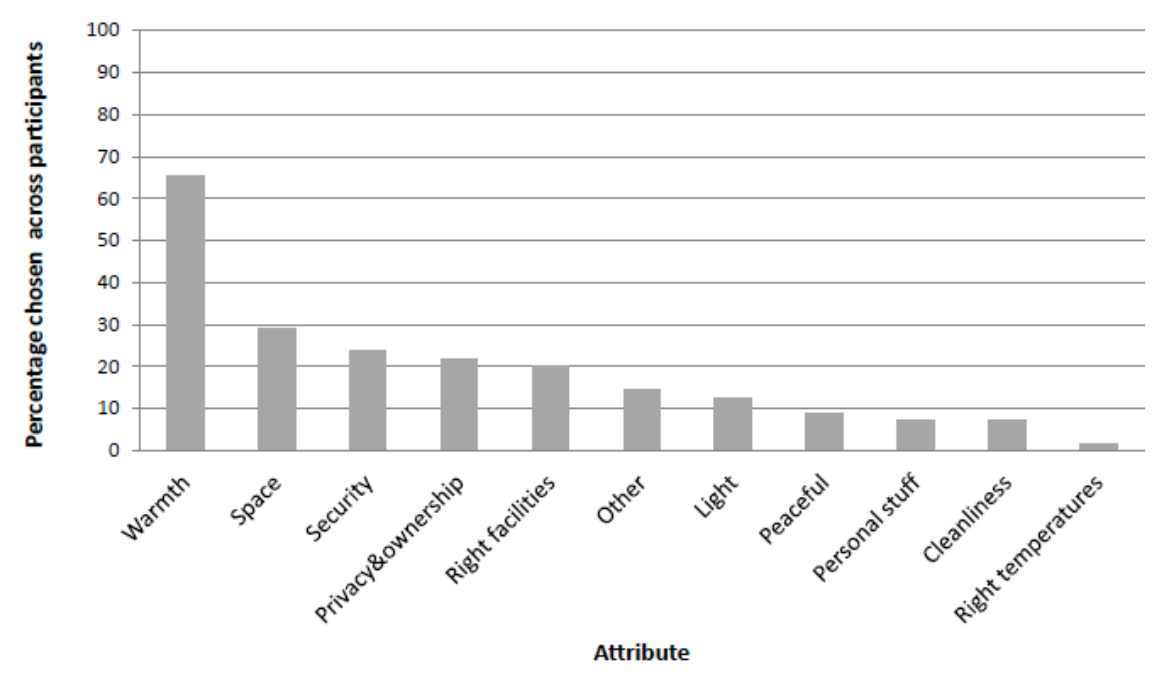

Note: Since multiple answers were possible, the total percentage is higher than 100

Comfort was defined as warmth by $65.50 \%$ of all participants, as having enough space by $29.10 \%$, as security by $23.64 \%$ and as a feeling of privacy and ownership by $21.82 \%$. When asked to identify the most important aspect of comfort, $45.45 \%$ of participants chose warmth and $16.67 \%$ security, followed by space and privacy and ownership. The predominance of warmth in defining comfort could potentially be a barrier towards energy reduction if comfortable temperatures were reached by relying on the heating system. The subsequent question in the questionnaire thus assessed which actions tenants 
performed in order to keep comfortable ( $N=40$; multiple answers possible). $75 \%$ of all answers were temperature-related and $60.00 \%$ referred to recreational actions such as playing with the cat or reading a book. Only very few of the answers referred to creating visual comfort, security related or other actions [see Figure 4(a)]. Figure 4(b) shows the distribution of temperature-related comfort actions in more detail.

Figure 4 (a) The percentage of participants who chose the comfort action as stated on the $x$-axis (b) A further differentiation of the temperature-related actions (see online version for colours)

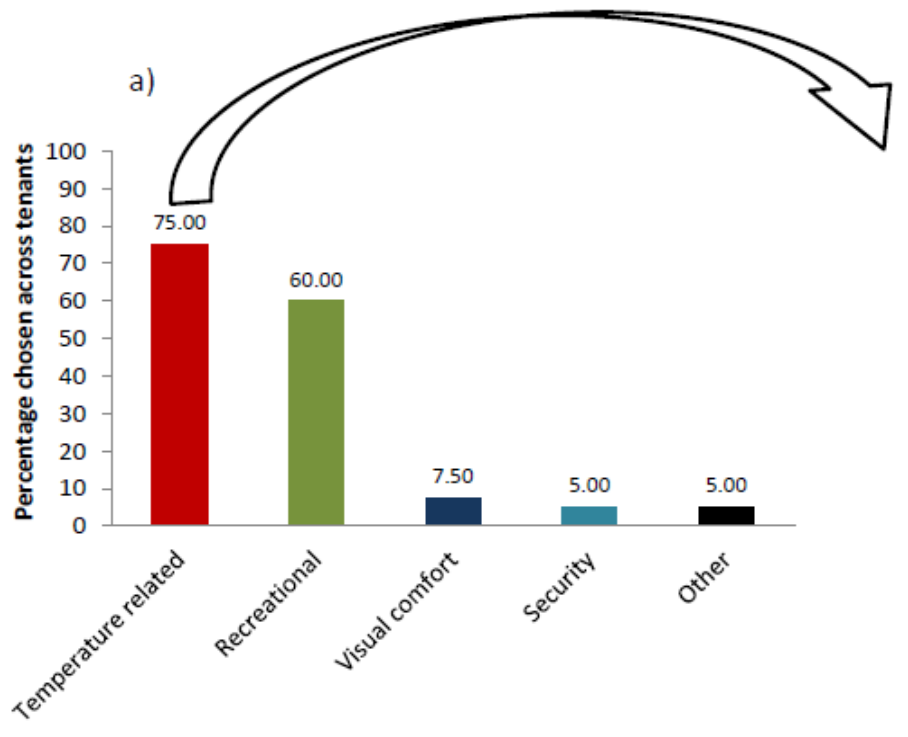

Type of action b)

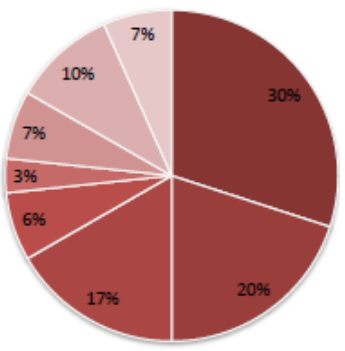

- Lots of clothes

- Blanket

- Hot drink

- Hot water bottle

- Electric blanket

- Heating up

Extra heater

- Open doors / windows

Half of all temperature-related actions did not consume any energy [Figure 4(b)], such as wearing lots of clothes or using a blanket to wrap up. Only $16.66 \%$ of reported temperature-related actions had presumably high energy consumption (turning the heating up and using an extra heater). Thus, whilst comfort is centred on warmth, the way to creating comfortable conditions is predominantly low in energy-costs. Also, recreational actions were given as comfort actions by a large proportion of participants, showing a very broad range of how to keep comfortable.

\subsection{Actions against feeling cold}

Participants were asked to state the first action they do when feeling cold. Figure 5 shows the distribution of answers; with the values on the y-axis indicating the percentage of participants who had chosen the respective action (one answer per participant).

The first three actions in the graph, printed in the darker hue, correspond to actions that do not consume energy; together they make up $52.7 \%$ of all answers. $42.0 \%$ of tenants engaged in energy-consuming actions as the first thing to do when feeling cold, as shown by the bars in the lighter hue. 
Figure 5 The y-axis shows the percentage of participants who chose the action given on the $\mathrm{x}$-axis as their first action when feeling cold (see online version for colours)

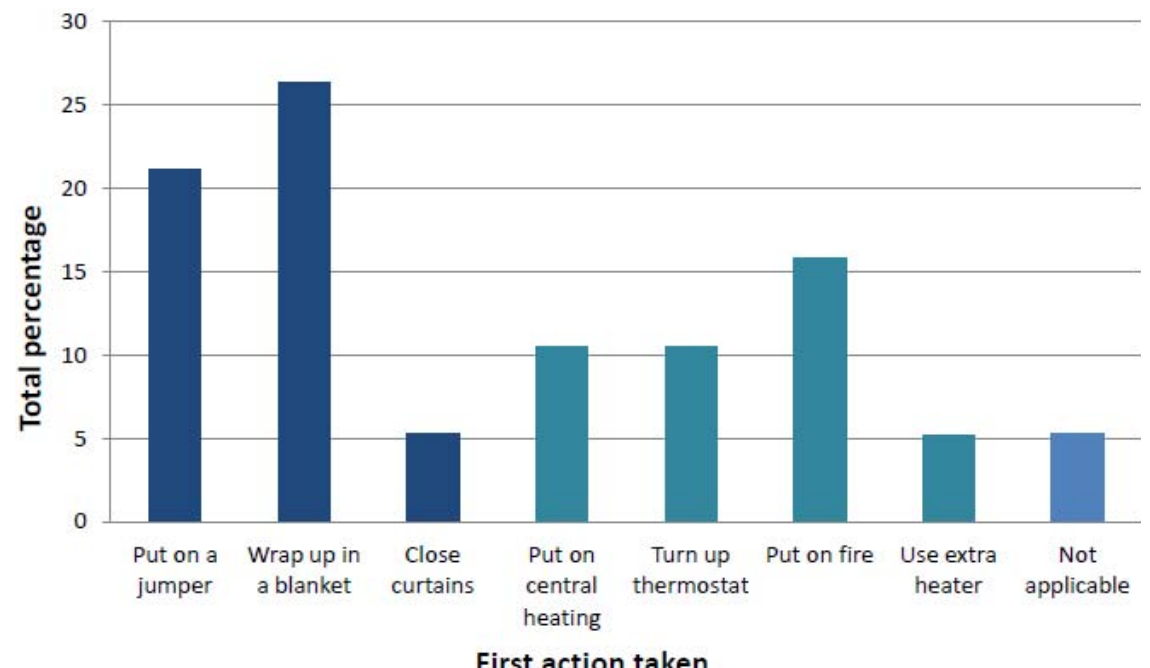

Taken together, the data on comfort, comfort actions and actions against cold showed that warmth is a central component for being comfortable but that the ways to reach comfort and to a lesser extent to fight off cold to a substantial part are not related to energy use. Engaging in actions to feel thermally comfortable are not identical to the first action when feeling cold, as indicated by the discrepancy between the answers to the respective questions on comfort actions and actions against cold.

\subsection{Building aspects}

Considering that space heating makes up the largest share of energy consumption in the house, knowledge of adequate control of the heating system is of great importance. Participants were asked in the interview if they had received instructions - written, verbal, demonstration, or a combination of the afore mentioned - about the correct usage of the heating system. $75 \%$ of the tenants $(N=40)$ indicated that they had received some sort of instruction upon moving in. $43 \%$ of those who had received instructions considered them to be 'not at all useful', the remaining $57.00 \%$ considered them as sufficiently good to control the heating system to meet their needs or called them 'okay'. Anecdotal data supported the finding that instructions were insufficient, as a number of participants asked for advice on how to best operate their heating sytem, such as whether it was better to keep it turned on all day but on a low temperature or whether to turn it on or off repeatedly during the day and if so whether via the thermostat or the actual on-off control.

The relationship between the general home satisfaction and the SAP rating of the building was examined. For $N=29$ households, both measurements were available. The mean SAP rating of those 29 households was $M=67.57(S D=12.23)$ and the mean home satisfaction $8.34(S D=2.13)$. These two variables were correlated to test if a higher SAP rating, a more energy-efficient home that is easier to keep warm, was associated with a greater home satisfaction. One-sided correlation analysis was used as expectations about 
the relationship were clear. Pearson's correlation coefficient was $r=-.140, n$.s. Figure 6 shows a scatter plot of the respective data.

Figure 6 The general home satisfaction (y-axis) is plotted against the SAP rating of the respective home (x-axis). note that not all data points are visible as the same combinations occured more than once (see online version for colours)

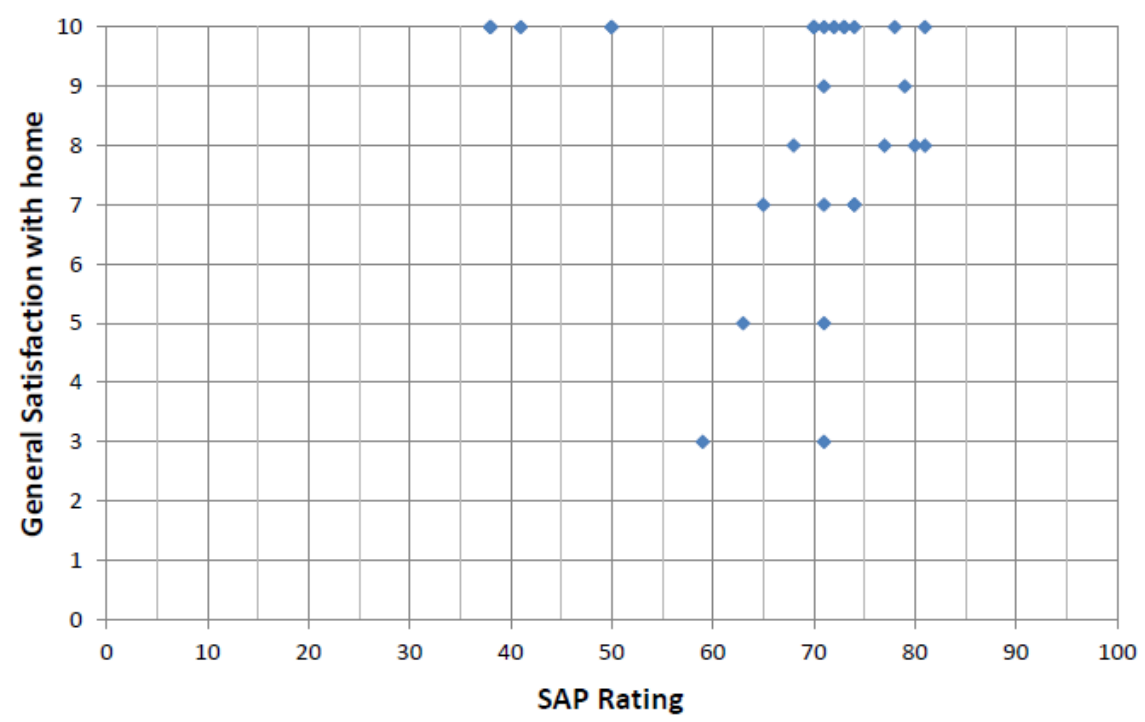

There was no significant correlation between home satisfaction and SAP rating, mainly due to the presence of several outliers where home satisfaction is very high but SAP rating low (five in total). Hence, the general conclusion has to be that there was no clear and significant relationship between home satisfaction and SAP rating, indicating that variables other than energy efficiency were of great importance for satisfaction with the home. The correlation between home satisfaction and satisfaction with the heating system just about reached significance, $r=.29, p=.049$, again indicating that despite the importance of warmth, other factors than a good heating system are crucial in determining home satisfaction.

\section{Discussion and conclusions}

The aim of this paper was to understand factors related to energy consumption in domestic buildings and to identify potential obstacles and motivators to reduce energy consumption in the household.

Data indicated that tenants to a large degree already engaged in energy-saving actions and were very willing to do so. Whilst this shows a positive attitude towards more sustainble behaviour, it could also indicate that further reduction in energy consumption via behaviour change might be difficult to achieve. However, it has to be kept in mind that participation in the study was voluntary; hence a selection bias is possible, with those tenants participating already more concerned about energy consumption. In any case, particular focus needs to be put on changing heating practices: very few tenants reported actively using their heating system less in order to save energy even though that action 
would have the largest impact. Habit, e.g., being used to behaving in a certain way was identified as the most important barrier towards saving energy and explained self-reported behaviour better than behavioural intentions. Warmth was identified as the most important component of comfort which is a potential barrier towards a reduction in energy consumption. However, analysis of comfort actions and actions against cold showed that to a large extent actions low in energy use were performed to be comfortable and fight off the cold. The discrepancy between thermal comfort actions and actions against cold is noteworthy, with the latter to a larger degree having high associated energy costs, namely using the heating system. The findings indicate that tenants perceived comfort, as in keeping warm, differently to feeling cold. Current data does not allow a more detailed understanding of where the difference lies. One possibility is that comfort is perceived as an increase of well-being whereas fighting the cold might be seen more as the removal of an unpleasant state, calling for more 'drastic measures'. Further research needs to address this issue. The data from the current study also showed no significant relationship between SAP rating and home satisfaction, indicating that the easiness with which a house can be kept warm is not the main determinant of satisfaction with the home. Another potential barrier to reducing energy consumption in the home was a lack of quantity and quality of instruction on how to use the heating system most efficiently. Money was identified as a strong motivator for saving energy.

The results indicate that social landlords should provide more guidance and better instruction on the most efficient operation of the heating system. Considering that most energy is used for space heating in the household (HM Government, 2006), knowledge on the best operation is crucial. About half the tenants who received instructions were unsure on how to best use the heating system; this finding is in line with findings of Liao et al. (2005) who identified insufficient knowledge about the usage of TRVs. It could be argued that tenants have forgotten the instructions provided by their landlord at some earlier point in time. However, a potential to forget should not relieve social housing landlords of their responsibility to provide information. In essence, social landlords need to reassess how they provide the information in the first place and to adjust its provision accordingly over time, e.g., increasing the frequency of information delivery. Another aspect in which landlords could influence their tenants' environmental behaviours is through breaking of habits. Habits are very efficient ways of reaching a goal as they occur automatically in the presence of goal-relevant cues; in the energy realm, a person might always switch on the light when entering the home or put the thermostat on at a certain time, even when current circumstances such as coming home early or the day being warmer than usual would make the behaviour unnecessary. Habits are generally difficult to change (e.g., Aarts and Dijksterhuis, 2000) and a change only in the goal intentions rarely leads to a change in habits (e.g., Aarts et al., 1997; Verplanken and Faes, 1999). One approach to changing habits is to change the situation (Bamberg, 2006; Dahlstrand and Biel, 1997), as then the habitual responses would not be triggered anymore. Landlords can change the context, for example when refurbishing a house or installing a new heating system and thus have the potential to break habits. Even for those changes which do not obviously change the triggers for a habitual response such as installing insulation (which is often invisible to the eye and does not in itself demand a change in the way activities are done), landlords could use the opportunity to facilitate a changing of habits. For example, the house might be less draughty following this improvement and hence a lower room temperature might be sufficient to achieve a comfortable environment. However, proactive engagement with the tenant would be 
required to provide this advice and allow the tenants to plan and implement a new heating strategy. Such an approach would be compatible with that suggested by Holland et al (2006) who identified detailed planning of how, when and where to carry out a new behaviour, such as recycling, was more successful in replacing habits than the mere decision to change a habit.

Previous research showed that people indicated that much of their energy consumption and heating practices were guided by habits (Maréchal, 2010). However, a literature research found no study relating habit to energy savings or consumption. In other areas, habit has been linked to behaviour and also incorporated into models (e.g., Bamberg et al., 2003; Klöckner and Matthies, 2004; Matthies et al., 2006); however, for domestic energy consumption further research is needed to understand the importance of habit and also test its incorporation into existing models of environmentally significant behaviour.

Saving money was seen as a strong motivator to save energy which at first glance might open up space for a powerful incentive to change behaviour. However, not only from a practical point, e.g., who would provide the necessary money, such an intervention would have to be debated. In general, results on financial incentives and the impact on intrinsic motivation are ambiguous [for reviews see e.g., Wiersma (1992), in experimental research, Camerer and Hogarth (1999)]. Some research indicates that changes in behaviour due to financial incentives are short-lived in nature (e.g., McClelland and Canter, 1981) and disappear upon withdrawal of the reward (Katzev and Johnson, 1987) which would make a continuous payment necessary. However, the importance of saving money might make it a promising approach to translate the energy saved through certain actions into money saved. Still, the possible occurrence of a rebound effect (Greening and Greene, 2000; Druckman et al., 2011), e.g., spending the money received or saved on unsustainable actions and thus offsetting any savings of carbon emissions, would still be a potential problem with a monetary incentive. In general, a replication of this part of the study in a tenant group outside social housing would be desirable to see if similar results emerge or whether they are specific to those with less disposable income such as the subgroup of social housing tenants.

The finding on comfort shows that thermal satisfaction has to be a crucial component in strategies aimed at reducing energy consumption. This is not to say that internal temperatures should not be lowered but that the emphasis should be on alternative ways of keeping comfortable. However, if such an approach would have any impact on energy consumption or even the opinion towards an energy-reduction campaign, remains to be seen. A second intriguing finding of the questions on comfort was that whilst warmth was the most important aspect, a number of different definitions emerged that fell outside the normally accepted comfort criteria of thermal, air quality, visual and acoustic comfort. Space, security, privacy and ownership were also identified as defining features of comfort and correspond to features of a home (for a review on the meaning of home, see e.g., Mallett, 2004) Thus, participants used a much wider definition of comfort than often employed in comfort research and reported actions of a recreational nature as comfort actions, e.g., actions with a positive impact on the person, highlighting the close link between comfort, well-being and quality of life. Consequently, there is a potential for misunderstandings between (academic) researchers and their subjects when speaking about comfort. Also, a mismatch might result when buildings are designed to correspond to the standard comfort criteria whereas the expectations and needs of home occupiers are quite different. Also, the research agenda on comfort might have to be widened to 
encompass this range of comfort meanings and actions, also with regard to energy consumption.

A limitation of the current study is that results have not been linked to actual energy consumption and that the sample was relatively small. Replication of the current findings in a larger and less specific sample is desirable to see if similar results would be obtained and hence more general conclusions be drawn.

In summary, from the current data, important barriers to changing behaviour have been identified that could help to understand energy savings better. The obligation and opportunity for landlords to pave the way for a more sustainable way of living have been discussed, to the authors' knowledge for the first time in the target group of social housing tenants.

\section{References}

Aarts, H. and Dijksterhuis, A. (2000) 'The automatic activation of goal-directed behaviour: the case of travel habit', Journal of Environmental Psychology, Vol. 20, No. 1, pp.75-82.

Aarts, H., Paulussen, T. and Schaalma, H. (1997) 'Physical exercise habit: on the conceptualization and formation of habitual health behaviours', Health Education Research, Vol. 12, No. 3, pp.363-374.

Abrahamse, W. and Steg, L. (2009) 'How do socio-demographic and psychological factors relate to households' direct and indirect energy use and savings?', Journal of Economic Psychology, Vol. 30, pp.711-720.

Ajzen, I. (1991) 'The theory of planned behavior', Organizational Behavior and Human Decision Processes, Vol. 50, No. 2, pp.179-211.

Armitage, C.J. and Conner, M. (2001) 'Efficacy of the theory of planned behaviour: a metaanalytic review', British Journal of Social Psychology, Vol. 40, No. 4, p.471.

ASHRAE (2010) Thermal Environmental Conditions for Human Occupancy, Standard 55-2010, ASHRAE Inc., Atlanta.

Bamberg, S. (2006) 'Is a residential relocation a good opportunity to change people's travel behavior? Results from a theory-driven intervention study', Environment and Behavior, Vol. 38, No. 6, pp.820-840.

Bamberg, S. and Schmidt, P. (2003) 'Incentives, morality, or habit? Predicting students' car use for university routes with the models of Ajzen, Schwartz, and Triandis', Environment and Behavior, Vol. 35, No. 2, pp.264-285.

Bamberg, S., Ajzen, I. and Schmidt, P. (2003) 'Choice of travel mode in the theory of planned behavior: the roles of past behavior, habit and reasoned action', Basic and Applied Social Psychology, Vol. 25, pp.175-187.

Bamberg, S., Hunecke, M. and Blöbaum, A. (2007) 'Social context, personal norms and the use of public transportation: two field studies', Journal of Environmental Psychology, Vol. 27, pp.190-203.

Brager, G.S. and de Dear, R.J. (1998) 'Thermal adaptation in the built environment: a literature review', Energy and Buildings, Vol. 27, No. 1, pp.83-96.

Busch, J.F. (1992) 'A tale of 2 populations - thermal comfort in air-conditioned and naturally ventilated offices in Thailand', Energy and Buildings, Vol. 18, Nos. 3-4, pp.235-249.

Camerer, C.F. and Hogarth, R.M. (1999) 'The effects of financial incentives in experiments: a review and capital-labor-production framework', Journal of Risk and Uncertainty, Vol. 19, Nos. 1-3, pp.7-42.

Chappells, H. and Shove, E. (2005) 'Debating the future of comfort: environmental sustainability, energy consumption and the indoor environment', Building Research and Information, Vol. 33, No. 1, pp.32-40. 
Cole, R.J., Robinson, J., Brown, Z. and O'Shea, M. (2008) 'Re-contextualizing the notion of comfort', Building Research and Information, Vol. 36, No. 4, pp.323-336.

Dahlstrand, U. and Biel, A. (1997) 'Pro-environmental habits: propensity levels in behavioral change', Journal of Applied Social Psychology, Vol. 27, No. 7, pp.588-601.

de Dear, R. and Brager, G.S. (2001) 'The adaptive model of thermal comfort and energy conservation in the built environment', International Journal of Biometeorology, Vol. 45, No. 2, pp.100-108.

de Groot, J. and Steg, L. (2007) 'Value orientations and environmental beliefs in five countries validity of an instrument to measure egoistic, altruistic and biospheric value orientations', Journal of Cross-Cultural Psychology, Vol. 38, No. 3, pp.318-332.

de Groot, J. and Steg, L. (2008) 'Value orientations to explain beliefs related to environmental significant behavior - how to measure egoistic, altruistic and biospheric value orientations', Environment and Behavior, Vol. 40, No. 3, pp.330-354.

Department for Communities and Local Government (2006) A Decent Home: Definition and Guidance for Implementation, Department for Communities and Local Government, London.

Department for Communities and Local Government (2008) Housing Statistics 2008 [online] http://www.communities.gov.uk/documents/statistics/pdf/1095351.pdf (accessed 30 April 2012).

Department for Communities and Local Government (2009) Survey of English Housing Preliminary Report: 2007/08 [online] http://www.communities.gov.uk/documents/statistics/ pdf/1133551.pdf (accessed 01 May 2012).

Department for Energy and Climate Change (2009) The UK Fuel Poverty Strategy [online] http://www.decc.gov.uk/assets/decc/Statistics/fuelpoverty/1_20091021091505_e_@@_UKFu elPovertyStrategy7AnnReport09.pdf (accessed 14 May 2015).

Department for Energy and Climate Change (2011) Energy Consumption in the United Kingdom, Department for Energy and Climate Change, London.

Druckman, A. and Jackson, T. (2008) 'Household energy consumption in the UK: a highly geographically and socio-economically disaggregated model', Energy Policy, Vol. 36, No. 8, pp.3177-3192.

Druckman, A., Chitnis, M., Sorrell, S. and Jackson, T. (2011) 'Missing carbon reductions? Exploring rebound and backfire effects in UK households', Energy Policy, Vol. 39, No. 6, pp.3572-3581.

Dunlap, R.E. and van Liere, K.D. (1978) 'The 'new environmental paradigm': a proposed measuring instrument and preliminary results', Journal of Environmental Education, Vol. 9, pp.10-19.

Dunlap, R.E., van Liere, K.D., Mertig, A.G. and Jones, R.E. (2000) 'Measuring endorsement of the new ecological paradigm: a revised NEP scale', Journal of Social Issues, Vol. 56, No. 3, pp.425-442.

Fanger, P. (1967) 'Calculation of thermal comfort: introduction of a basic comfort equation', ASHRAE Transactions, Vol. 73, No. 2, p.73, II:III.4.1.

Fanger, P. (1970) Thermal comfort - Analysis and Applications in Environmental Engineering, Danish Technical Press, Copenhagen.

Gärling, T., Fuijii, S., Gärling, A. and Jakobsson, C. (2003) 'Moderating effects of social value orientation on determinants of proenvironmental behavior intention', Journal of Environmental Psychology, Vol. 23, No. 1, pp.1-9.

Gatersleben, B., Steg, L. and Vlek, C. (2002) 'Measurement and determinants of environmentally significant consumer behavior', Environment \& Behavior, Vol. 34, No. 3, pp.335-362.

Gill, Z.M., Tierney, M.J., Pegg, I.M. and Allan, N. (2010) 'Low-energy dwellings: the contribution of behaviours to actual performance', Building Research and Information, Vol. 38, No. 5, pp.491-508.

Greening, L.A. and Greene, D.L. (2000) 'Energy efficiency and consumption-the rebound effect-a questionnaire', Energy Policy, Vol. 28, Nos. 6/7, pp.389-401. 
Guagnano, G.A. and Stern, P.C. (1995) 'Influences on attitude-behavior relationships: a natural experiment with curbside recycling', Environment \& Behavior, Vol. 27, No. 5, pp.699-718.

Harland, P., Staats, H. and Wilke, H.A.M. (1999) 'Explaining proenvironmental intention and behavior by personal norms and the theory of planned behavior', Journal of Applied Social Psychology, Vol. 29, No. 12, pp.2505-2528.

HM Government (2006) Climate Change: The UK programme 2006, The Stationary Office, London.

Holland, R.W., Aarts, H. and Langendam, D. (2006) 'Breaking and creating habits on the working floor: a field-experiment on the power of implementation intentions', Journal of Experimental Social Psychology, Vol. 42, No. 6, pp.776-783.

Hopper, J.R. and Nielsen, J.M. (1991) 'Recycling as altruistic behavior: normative and behavioral strategies to expand participation in a community recycling program', Environment and Behavior, Vol. 23, No. 2, pp.195-220.

Kaiser, F.G. and Gutscher, H. (2003) 'The proposition of a general version of the theory of planned behavior: predicting ecological behavior', Journal of Applied Social Psychology, Vol. 33, No. 3, pp.586-603.

Kaiser, F.G., Hübner, G. and Bogner, F.X. (2005) 'Contrasting the theory of planned behavior with the value-belief-norm model in explaining conservation behavior', Journal of Applied Social Psychology, Vol. 35, No. 10, pp.2150-2170.

Katzev, R.D. and Johnson, T.D. (1987) Promoting Energy Conservation: An Analysis of Behavioral Research, Westview Press, Boulder, CO.

Klöckner, C.A. and Matthies, E. (2004) 'How habits interfere with norm directed behaviour - a normative decision-making model for travel mode choice', Journal of Environmental Psychology, Vol. 24, pp.319-327.

Liao, Z., Swainson, M. and Dexter, A. L. (2005) 'On the control of heating systems in the UK', Building and Environment, Vol. 40, No. 3, pp.343-351.

Mallett, S. (2004) 'Understanding home: a critical review of the literature', Sociological Review, Vol. 52, No. 1, pp.62-89.

Maloney, M.P., Ward, M.P. and Braught, G.N. (1975) 'A revised scale for the measurement of ecological attitudes and knowledge', American Psychologist, Vol. 30, pp.787-790.

Maréchal, K. (2010) 'Not irrational but habitual: the importance of 'behavioural lock-in' in energy consumption', Ecological Economics, Vol. 69, pp.1104-1114.

Matthies, E., Klöckner, C.A. and Preißner, C. (2006) 'Applying a modified moral decision making model to change habitual car use - how can commitment be effective?', Applied Psychology, Vol. 55, pp.91-106.

McClelland, L. and Canter, R.J (1981) 'Psychological research on energy conservation: context, approaches, methods', in Baum, A. and Singer, J.E. (Eds.): Advances in Environmental Psychology: Volume 3. Energy Conservation: Psychological Perspectives, Lawrence Erlbaum, Hillsdale, NJ.

Nordlund, A.M. and Garvill, J. (2003) 'Effects of values, problem awareness and personal norm on willingness to reduce personal car use', Journal of Environmental Psychology, Vol. 23, No. 4, pp.339-347.

Poortinga, W., Steg, L. and Vlek, C. (2004) 'Values, environmental concern and environmental behavior - a study into household energy use', Environment and Behavior, Vol. 36, No. 1, pp.70-93.

Rutter, J. and Latorre, M. (2009) Social Housing Allocation and Immigrant Communities, Report: Institute for Public Policy Research, London.

Schultz, P.W. and Zelezny, L. (1999) 'Values as predictors of environmental attitudes: evidence for consistency across 14 countries', Journal of Environmental Psychology, Vol. 19, No. 3, pp.255-265.

Schwartz, S.H. (1977) 'Normative influences on altruism', in Berkowitz, L. (Ed.): Advances in Experimental Social Psychology, pp.221-279, Academic Press, New York. 
Seligman, C., Darley, J. and Becker, L. (1978) 'Behavioral approaches to residential energy', Energy and Buildings, Vol. 1, No. 3, pp.325-337.

Sharma, M. and Ali, S. (1986) 'Tropical summer index - a study of thermal comfort of Indian subjects', Building and Environment, Vol. 21, No. 1, pp.11-24.

Shorrock, L.D. and Utley, J.I. (2008) Domestic Energy Fact File 2008, Building Research Establishment, Watford.

Shove, E., Chappells, H., Lutzenhiser, L. and Hackett, B. (2008) 'Comfort in a lower carbon society', Building Research and Information, Vol. 36, No. 4, pp.307-311.

Steg, L., Dreijerink, L. and Abrahamse, W. (2005) 'Factors influencing the acceptability of energy policies: a test of VBN theory', Journal of Environmental Psychology, Vol. 25, No. 4, pp.415-425.

Stern, P.C. (2000) 'Toward a coherent theory of environmentally significant behavior', Journal of Social Issues, Vol. 56, No. 3, pp.407-424.

Stern, P.C. and Dietz, T. (1994) 'The value basis of environmental concern', Journal of Social Issues, Vol. 50, No. 3, pp.65-84.

Stern, P.C., Dietz, T., Abel, T., Guagnano, G.A. and Kalof, L. (1999) 'A value-belief-norm theory of support for social movements: the case of environmentalism', Human Ecology Review, Vol. 6, No. 2, pp.81-97.

Stern, P.C., Dietz, T., Kalof, L. and Guagnano, G.A. (1995) 'Values, beliefs and proenvironmental action: attitude formation toward emergent attitude objects', Journal of Applied Social Psychology, Vol. 25, No. 18, pp.1611-1636.

Utley, I.J. and Shorrock, L.D. (2006) Domestic energy Fact File: Owner Occupied, Local Authority, Private Rented and Registered Social Landlord Homes, Building Research Establishment, Watford.

van Hoof, J., Mazej, M. and Hensen, J.L.M. (2010) 'Thermal comfort: research and practice', Frontiers in Bioscience-Landmark, Vol. 15, pp.765-788.

Verplanken, B. and Faes, S. (1999) 'Good intentions, bad habits and effects of forming implementation intentions on healthy eating', European Journal of Social Psychology, Vol. 29, Nos. 5-6, pp.591-604.

Vining, J. and Ebreo, A. (1992) 'Predicting recycling behavior from global and specific environmental attitudes and changes in recycling opportunities', Journal of Applied Social Psychology, Vol. 22, No. 20, pp.1580-1607.

Wiersma, U.J. (1992) 'The effects of extrinsic rewards in intrinsic motivation - a metaanalysis', Journal of Occupational and Organizational Psychology, Vol. 65, pp.101-114.

Yohanis, Y., Mondol, J., Wright, A. and Norton, B. (2008) 'Real-life energy use in the UK: how occupancy and dwelling characteristics affect domestic electricity use', Energy and Buildings, Vol. 40, No. 6, pp.1053-1059. 


\section{Appendix A}

\section{Questionnaire}

Please put a tick in the box that correctly identifies how much you agree or disagree with each statement

\begin{tabular}{|c|c|c|c|c|c|}
\hline & $\begin{array}{l}\text { Strongly } \\
\text { Agree }\end{array}$ & Agree & $\begin{array}{l}\text { Neither } \\
\text { agree nor } \\
\text { disagree }\end{array}$ & Disagree & $\begin{array}{l}\text { Strongly } \\
\text { disagree }\end{array}$ \\
\hline \multicolumn{6}{|l|}{ Behavioural intentions } \\
\hline $\begin{array}{l}\text { I would be willing to wear an extra } \\
\text { jumper to keep warm rather than } \\
\text { turning up the heating to save energy. }\end{array}$ & $\square$ & $\square$ & $\square$ & $\square$ & $\square$ \\
\hline $\begin{array}{l}\text { To save energy, I would be willing to } \\
\text { use energy saving light bulbs. }\end{array}$ & $\square$ & $\square$ & $\square$ & $\square$ & $\square$ \\
\hline $\begin{array}{l}\text { I would be willing to watch less } \\
\text { television to save energy. }\end{array}$ & $\square$ & $\square$ & $\square$ & $\square$ & $\square$ \\
\hline $\begin{array}{l}\text { I would be willing to hang my washing } \\
\text { outside to get dry in the summer rather } \\
\text { than inside, if facilities were provided. }\end{array}$ & $\square$ & $\square$ & $\square$ & $\square$ & $\square$ \\
\hline $\begin{array}{l}\text { To save electricity I would be willing to } \\
\text { switch the TV off completely when not } \\
\text { using it. }\end{array}$ & $\square$ & $\square$ & $\square$ & $\square$ & $\square$ \\
\hline $\begin{array}{l}\text { I would be willing to use a water-saving } \\
\text { shower head if provided. }\end{array}$ & $\square$ & $\square$ & $\square$ & $\square$ & $\square$ \\
\hline $\begin{array}{l}\text { I would be willing to turn the shower } \\
\text { off while I am soaping myself. }\end{array}$ & $\square$ & $\square$ & $\square$ & $\square$ & $\square$ \\
\hline $\begin{array}{l}\text { I would be willing to more frequently } \\
\text { wash laundry at } 30 \text { or } 40 \text { degrees } \\
\text { instead of } 60 \text {. }\end{array}$ & $\square$ & $\square$ & $\square$ & $\square$ & $\square$ \\
\hline $\begin{array}{l}\text { I would be willing to lower the } \\
\text { thermostat setting by one degree. }\end{array}$ & $\square$ & $\square$ & $\square$ & $\square$ & $\square$ \\
\hline \multicolumn{6}{|l|}{ Behavioural actions } \\
\hline $\begin{array}{l}\text { I frequently use extra blankets or } \\
\text { jumpers rather than turning up the } \\
\text { heating. }\end{array}$ & $\square$ & $\square$ & $\square$ & $\square$ & $\square$ \\
\hline $\begin{array}{l}\text { I leave the fridge door open while I am } \\
\text { deciding what to get out. }\end{array}$ & $\square$ & $\square$ & $\square$ & $\square$ & $\square$ \\
\hline $\begin{array}{l}\text { I often leave lights on even when I } \\
\text { leave the room. }\end{array}$ & $\square$ & $\square$ & $\square$ & $\square$ & $\square$ \\
\hline $\begin{array}{l}\text { I usually put a lid on pots when cooking } \\
\text { something that does not need to be } \\
\text { stirred. }\end{array}$ & $\square$ & $\square$ & $\square$ & $\square$ & $\square$ \\
\hline $\begin{array}{l}\text { I keep my mobile phone charger } \\
\text { plugged in to the socket when I am not } \\
\text { charging the phone. }\end{array}$ & $\square$ & $\square$ & $\square$ & $\square$ & $\square$ \\
\hline $\begin{array}{l}\text { I switch the TV off completely when I } \\
\text { am done watching it. }\end{array}$ & $\square$ & $\square$ & $\square$ & $\square$ & $\square$ \\
\hline
\end{tabular}


Please put a tick in the box that correctly identifies how much you agree or disagree with each statement (continued)

\begin{tabular}{|c|c|c|c|c|c|}
\hline & $\begin{array}{l}\text { Strongly } \\
\text { Agree }\end{array}$ & Agree & $\begin{array}{l}\text { Neither } \\
\text { agree nor } \\
\text { disagree }\end{array}$ & Disagree & $\begin{array}{l}\text { Strongly } \\
\text { disagree }\end{array}$ \\
\hline \multicolumn{6}{|l|}{ Behavioural actions } \\
\hline $\begin{array}{l}\text { I use the radiators to dry wet clothes in } \\
\text { summer. }\end{array}$ & $\square$ & $\square$ & $\square$ & $\square$ & $\square$ \\
\hline $\begin{array}{l}\text { When using a water kettle, I only heat } \\
\text { the amount of water I need. }\end{array}$ & $\square$ & $\square$ & $\square$ & $\square$ & $\square$ \\
\hline \multicolumn{6}{|l|}{$\begin{array}{l}\text { Motivation to reduce energy } \\
\text { consumption }\end{array}$} \\
\hline $\begin{array}{l}\text { I would be willing to reduce my energy } \\
\text { consumption in order to save money. }\end{array}$ & $\square$ & $\square$ & $\square$ & $\square$ & $\square$ \\
\hline $\begin{array}{l}\text { I would be willing to reduce my energy } \\
\text { consumption in order to protect the } \\
\text { environment. }\end{array}$ & $\square$ & $\square$ & $\square$ & $\square$ & $\square$ \\
\hline $\begin{array}{l}\text { I would be willing to reduce my energy } \\
\text { consumption in order to keep the planet } \\
\text { liveable for future generations. }\end{array}$ & $\square$ & $\square$ & $\square$ & $\square$ & $\square$ \\
\hline \multicolumn{6}{|l|}{ Barriers to saving energy } \\
\hline It is inconvenient to save energy. & $\square$ & $\square$ & $\square$ & $\square$ & $\square$ \\
\hline $\begin{array}{l}\text { My friends do not save energy so I don } \\
\text { not see why I should. }\end{array}$ & $\square$ & $\square$ & $\square$ & $\square$ & $\square$ \\
\hline It takes too much time to save energy. & $\square$ & $\square$ & $\square$ & $\square$ & $\square$ \\
\hline $\begin{array}{l}\text { The money saved by using less energy } \\
\text { is very little. }\end{array}$ & $\square$ & $\square$ & $\square$ & $\square$ & $\square$ \\
\hline I am used to behaving in a certain way. & $\square$ & $\square$ & $\square$ & $\square$ & $\square$ \\
\hline I do not know how to save energy. & $\square$ & $\square$ & $\square$ & $\square$ & $\square$ \\
\hline Saving energy is expensive. & $\square$ & $\square$ & $\square$ & $\square$ & $\square$ \\
\hline There is no point in saving energy. & $\square$ & $\square$ & $\square$ & $\square$ & $\square$ \\
\hline
\end{tabular}

\section{Appendix B}

\section{Interview}

- Focusing on your home, could you describe in your own words what it means to be comfortable?

- Which of the aspects you have mentioned is most important to you?

- Can you tell me about what you do to feel comfortable?

- What is your first action when you start to feel cold? 
- What type of heating system do you have?

- How would you rate your heating system for its ability to heat your home to a satisfactory level? - say between 1 and 10 (10 being completely satisfied).

- How would you rate your home for its ability to keep you feeling comfortable again on a scale from $1-10$ ?

- Do you do anything to use less energy? If so what? 